\title{
A precarização das condiç̧̃̃es de trabalho dos jornalistas de São Paulo segmentada por faixas etárias Uma identidade profissional em risco? ${ }^{1}$
}

\author{
Thales Vilela Lelo* \\ http://orcid.org/0000-0002-6070-9332
}

Introdução

O presente artigo é orientado pelo objetivo de compreender como a identidade profissional dos membros do campo jornalístico é reconfigurada à luz de um cenário de reestruturações nas organizações de mídia e de remodelações em seus modelos de gestão. Para tanto, foi realizada uma investigação empírica, que envolveu a aplicação de dois questionários e 15 entrevistas semiestruturadas, com jornalistas profissionais que atuavam no Estado de São Paulo entre dezembro de 2015 e janeiro de $2017^{2}$. Em específico, pretende-se argumentar que a proliferação dos processos de demissão em massa em alguns dos principais veículos de imprensa (em seus mais variados suportes) de São Paulo, além de mobilizar uma deterioração acentuada das condições de trabalho no setor (acompanhada de alta rotatividade de contratos e enxugamento de postos e salários), atinge em particular a estabilidade dos cargos tipicamente ocupados por profissionais de maior experiência na área, em tese responsáveis por transmitir a "cultura do ofício" às novas gerações de repórteres.

* Universidade do Estado de Minas Gerais, Divinópolis, Minas Gerais, Brasil.

1. Este trabalho contou com o apoio do Conselho Nacional de Desenvolvimento Científico e Tecnológico (CNPq), da Federação Nacional dos Jornalistas (Fenaj), e do Sindicato dos Jornalistas Profissionais do Estado de São Paulo (sJsp).

2. O presente texto é excerto de uma pesquisa mais extensa, intitulada "Reestruturações produtivas no mundo do trabalho dos jornalistas: precarização, tecnologia e manifestações da identidade profissional" (2015-2018). Para este trabalho somente uma parcela dos dados coletados foi analisada, em consonância aos objetivos do texto. 
A despeito do fato de que o jornalismo venha recorrentemente figurando na lista de "piores empregos do ano" nos Estados Unidos segundo o site CareerCast ${ }^{3}$ tendo sido considerada a ocupação mais desfavorável segundo o ranking do portal (composto de 200 profissões) nos anos de 2013, 2015, 2016 e $2017^{4}$-, é notório o fato de que, na literatura especializada, por muitas décadas houve certo desinteresse em abordar o jornalismo do ponto de vista do trabalho e, sobretudo, pelo prisma das reestruturações produtivas que paulatinamente reconfiguraram o setor. Salvo raras exceções, nos estudos clássicos da sociologia do jornalismo há, de um lado, um destaque acentuado nos critérios de filtragem e definição dos tipos de acontecimento aptos a receberem cobertura noticiosa (Gans, 1979; Tuchman, 1973), de outro, atenção privilegiada é conferida às práticas de socialização em uma cultura profissional caracterizada por valores éticos estrategicamente acionados na resolução de impasses vivenciados cotidianamente (Bourdieu, 1996; Traquina, 2005), e aos processos de progressiva formalização do campo jornalístico (Ruellan, 2004).

Ao longo dos anos 2000, ao menos no contexto nacional, o lastro de estudos dedicados a apreender as mutações nas empresas de comunicação a partir do advento do jornalismo online foi consideravelmente ampliado, seja para questionar o contraste entre os princípios deontológicos estabelecidos pelo campo e as práticas de publicação pautadas pelo ascendente fetiche do "tempo real" (Moretszohn, 2002); seja para descrever as mudanças na identidade do jornalista e em suas condições de trabalho nesse novo horizonte (Adghirni, 2001). Nos últimos anos, tais estudos ganharam popularidade e já não ocupam mais a periferia das pesquisas em jornalismo, sobretudo porque os efeitos das reestruturações produtivas nesse setor já são salientes demais para serem legados à margem.

No cenário recente brasileiro, as transformações no mundo do trabalho dos jornalistas se fazem mais visíveis devido à alta rotatividade de profissionais nas redações de veículos de comunicação de grande e médio porte, alimentada por ondas de demissão em massa (também chamadas de "passaralhos" no grupo profissional ${ }^{5}$ ): segundo pesquisa do Volt Data Lab ${ }^{6}$, ao menos 1836 comunicadores foram demitidos entre os anos de 2012 e 2017 (Gráfico 1).

3. Disponível em: http://www.careercast.com/.

4. A metodologia adotada para o levantamento dos dados envolve, em geral, métricas de renda, oportunidades de ascensão na carreira, condições laborais e de saúde.

5. O jargão surgiu em 1975 após uma avalanche de demissões ocorridas no antigo Jornal do Brasil, em analogia às revoadas de pássaros que destroem tudo pelo caminho onde passam. Para mais informações, ver: http://apublica.org/2013/06/revoada-dos-passaralhos/

6. Disponível em: http://passaralhos.voltdata.info/graficos.html. 
GRÁFICO 1

Demissões em veículos de mídia no Brasil (2012-2017)

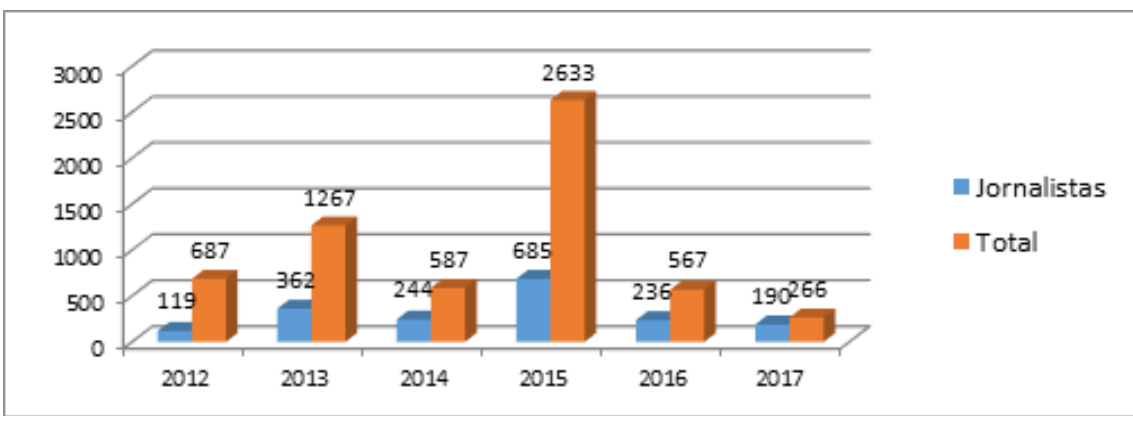

Nota: Os dados de 2017 correspondem até abril.

Fonte: Levantamento Volt Data Lab?

Evidencia-se aqui o processo discutido por Huws (2014) de geração de um "exército de reserva" que atua como força disciplinar no ímpeto de embaratecer a mão de obra disponível e viabilizar formas de contratação flexíveis (como freelancers, atuação como Pessoa Jurídica - PJ, contratos temporários e por prestação de serviços etc.). Esse quadro de flexibilização se delineia no Brasil também por meio do paulatino declínio no índice de registros profissionais de novos jornalistas (condição para a $\operatorname{CLT}^{8}$ ), disponibilizado pela Coordenação de Identificação e Registro Profissional (Cirp) 9 .

À luz desses dados no mínimo alarmantes, nas seções seguintes serão inicialmente elucidados os procedimentos metodológicos adotados no decurso da pesquisa realizada com repórteres do Estado de São Paulo, e em seguida será empreendida uma incursão aos dados coletados, visando, inicialmente, apreender os impactos das reestruturações produtivas no mundo do trabalho dos jornalistas no que diz respeito a aspectos das condições laborais (rendimento médio, extensão das jornadas, necessidade de complementação da renda familiar por meio de outras atividades, mobilidade de postos e formas de contratação). Em seguida, pretende-se deslindar um processo contemporâneo de desconexão da "identidade jornalística" da tradição de saberes, valores e códigos deontológicos que forjaram sua cultura profissional: a

7. Como ponderam os realizadores desse levantamento, há que se levar em conta uma subnotificação da porcentagem real de jornalistas dispensados nos últimos anos, seja porque muitas das notas que compuseram o corpus de análise não discriminaram o número exato de comunicadores dispensados, ou ainda porque há elevada informalidade na área que inviabiliza contabilizar como demissão a exoneração de um profissional contratado como Pessoa Jurídica (PJ) ou terceirizado (pois não se trata de funcionário direto da empresa).

8. Consolidação das Leis do Trabalho.

9. Disponível em: https://medium.com/volt-data-lab/a-conta-dos-passaralhos-953e7e254d4a. 
precarização ascendente dos mais experientes no setor estaria gerando obstáculos à socialização dos ingressantes na carreira.

\section{Metodologia}

Tendo no horizonte que a preocupação crucial desta investigação é apreender dimensões das reestruturações produtivas no mundo do trabalho dos jornalistas do Estado de São Paulo (alinhadas às reconfigurações na identidade profissional desses atores sociais), evidencia-se notadamente um enfoque privilegiado nas experiências dos sujeitos que compõem essa categoria ocupacional. Por essa razão, a via metodológica privilegiada de incursão ao campo é a qualitativa, no sentido delimitado por Minayo e Sanches (1993): “A abordagem qualitativa só pode ser empregada para a compreensão de fenômenos específicos e delimitáveis mais pelo seu grau de complexidade interna do que pela sua expressão quantitativa” (p. 245). Para os autores, essa perspectiva permite então "aprofundar a complexidade de fenômenos, fatos e processos particulares e específicos de grupos mais ou menos delimitados em extensão e capazes de serem abrangidos intensamente" (Minayo e Sanches, 1993, p. 247).

Definida a abordagem prioritária de acesso ao universo empírico, o recorte geográfico definido para análise justifica-se a partir dos resultados da extensa investigação desenvolvida por Mick e Lima (2013) acerca da estruturação do mercado de trabalho dos jornalistas no Brasil nos últimos anos. Segundo dados desse trabalho, entre 1980 e 2011 São Paulo concentrou mais de 36\% dos registros distribuídos em todo o país, o que sinaliza uma presença mais volumosa de profissionais da área nessa região.

\section{Questionário "Perfil dos jornalistas profissionais do Estado de São Paulo"}

De posse dessa circunscrição espacial, foi elaborado um primeiro questionário (por meio da plataforma Survio), intitulado "Perfil dos jornalistas profissionais do Estado de São Paulo". A enquete foi composta de 26 questões objetivas organizadas em quatro segmentos: (a) perfil social; (b) perfil profissional; (c) condições de trabalho; (d) condições de saúde. Duas questões adicionais foram acrescidas a esse conjunto, uma primeira indagando o interesse do respondente em participar em etapas posteriores da pesquisa e uma segunda com uma caixa de comentários aberta para que o participante escrevesse aquilo que lhe aprouvesse.

Importante salientar que o propósito de elaboração desse questionário não foi o de quantificar, com rigor estatístico, dados que permitissem construir um perfil socioeconômico preciso dos jornalistas que atuam no Estado de São Paulo. Tendo 
em vista o próprio fio condutor da pesquisa, a aplicação desta enquete teve como objetivos fulcrais a atualização e a comparação dos dados coletados com aqueles oriundos de investigações similares desenvolvidas em outros períodos (Heloani, 2005; Fígaro, 2013) e com recortes geográficos distintos (Pereira, 2013; Mick e Lima, 2013); e a procura por interlocutores promissores para etapas ulteriores da pesquisa, que assinalavam seu interesse em contribuir com o trabalho por meio do referido questionário.

O período de aplicação da enquete foi de 10 meses (de 11 de novembro de 2015 a 24 de setembro de 2016). Foram obtidas 260 contribuições, mas desse total 22 fichas tiveram que ser descartadas por não se enquadrarem no escopo da pesquisa (majoritariamente jornalistas oriundos de outros Estados da Federação e fichas duplicadas), restando 238 réplicas válidas.

Uma leitura geral do perfil dos respondentes desse primeiro questionário assinala uma correspondência com tendências já detectadas em outras investigações de mesmo escopo, tanto em cenário brasileiro quanto global (Fígaro, 2013; Mick e Lima, 2013; Neveu, 2000; Ruellan, 2001). Há uma preponderância de mulheres, jovens (entre 19 e 30 anos), solteiras, sem dependentes e com ensino superior completo: $64 \%$ dos colaboradores se identificavam como do sexo feminino e quase metade (46\%) da amostra se encontrava na faixa de 19 a 30 anos $^{10}$. Já no que diz respeito ao estado civil, novamente mais da metade dos respondentes (56,3\%) assinalou a opção "solteiro", dado que, em certa medida, converge com o alto índice de jovens entre os comunicadores. A segunda opção mais registrada foi "casado", preenchendo 28,6\% do total. As demais alternativas (divorciado, união livre e viúvo) somaram juntas $15,1 \%$ do percentual. A esmagadora maioria dos respondentes também assinalou não ter nenhum dependente. Os índices, nesse caso, chegaram à casa dos $71 \%$, enquanto os comunicadores com dependentes corresponderam a somente $29 \%$ da amostra. Dentre os 238 participantes, $94 \%$ possuíam formação superior.

\section{Questionário "Condições de trabalho dos jornalistas profissionais do Estado de São Paulo"}

Um segundo questionário foi aplicado visando obter dados referentes às características dos vínculos empregatícios dos comunicadores do Estado. Intitulado "Condições de trabalho dos jornalistas profissionais do Estado de São Paulo", esse questionário complementar foi composto por oito questões: sexo; idade; cidade; cargo; forma

10. Na sequência, entre 31 e 40 anos, foram registrados $28 \%$ dos comunicadores. No segmento de 41 a 50 anos, somente $14 \%$ do total, enquanto $12 \%$ correspondiam ao subgrupo de 51 a 70 anos. 
de contratação; férias e recebimento de $13^{\circ 11}$. Algumas das seções (como cargo e formas de contratação) permitiam que o respondente assinalasse mais de uma opção disponível, já antecipando a possibilidade que os profissionais assumissem mais de um cargo nas empresas em que atuam ou ainda possuíssem múltiplos vínculos contratuais - expectativa que se confirmou em posterior análise dos dados obtidos.

O questionário, desenvolvido dessa vez na plataforma da Google (Formulários Google), começou a ser aplicado em 7 de dezembro de 2016 e foi considerado finalizado em 26 de janeiro de 2017, acumulando um total de 330 fichas de resposta. Os dados foram posteriormente organizados e 12 fichas tiveram de ser excluídas por serem duplicadas ou corresponderem a outros Estados da Federação, totalizando 318 respostas válidas. Os resultados atinentes às formas de contratação foram posteriormente segmentados para análise com recorte por faixa etária, possibilitando eventuais comparaçôes de disparidade nos vínculos empregatícios entre jovens e profissionais de maior experiência no setor. Cabe pontuar que, no que tange à divisão dos respondentes por gerações, nesse questionário houve uma predominância por comunicadores na faixa etária de 31 a 40 anos ( $31 \%$ do total), seguidos por profissionais de 51 a 60 anos (23\% da amostra) e pelos mais jovens, de 19 a 30 anos (22\%). O segmento de 41 a 50 anos atingiu 15\% do percentual de respondentes, e somente $9 \%$ se encontravam no estrato de 61 a 70 anos.

\section{Entrevistas semiestruturadas}

O emprego de entrevistas em pesquisas orientadas por abordagens qualitativas é recorrente, como destacam Duarte (2004) e Minayo e Sanches (1993), haja vista que "o material primordial da investigação qualitativa é a palavra que expressa a fala cotidiana, seja nas relações afetivas e técnicas, seja nos discursos intelectuais, burocráticos e políticos" (Minayo e Sanches, 1993, p. 245). Os autores salientam que os discursos que transbordam das respostas às questóes formuladas pelo pesquisador revelam não somente as trajetórias individuais dos sujeitos, mas também as condições estruturais nas quais se inserem e os sistemas de valores que configuram seus modos de interpretar o mundo.

Foi efetuada uma nova delimitação do corpus para seleção dos possíveis entrevistados que iriam compor o quadro de análise. A escolha dos interlocutores que compuseram essa etapa da pesquisa obedeceu a duas diretrizes: (a) estabelecer contato com sujeitos que tivessem participado do primeiro questionário aplicado aos comunicadores do Estado e se oferecido para colaborarem na etapa de entrevistas

11. Neste artigo somente os dados referentes às formas de contratação serão analisados. 
(indicando seu e-mail para comunicação); (b) entrar em contato com profissionais indicados por colegas entrevistados previamente e que estivessem em conformidade aos parâmetros geográficos estipulados pelo pesquisador ${ }^{12}$.

O roteiro elaborado para essa fase da investigação foi composto de cinco subgrupos de indagações (formação; trajetória profissional; condições de trabalho; condições de saúde; percepções gerais sobre a área) enfocadas em estimular um depoimento da experiência profissional do entrevistado em um mercado em profunda reestruturação ${ }^{13}$. Entre 11 de abril e 12 de setembro de 2016 foram realizadas 15 entrevistas via Skype com profissionais com passagens em alguns dos principais veículos de comunicação brasileiros baseados em São Paulo ${ }^{14}$. Todas as fontes atuam ou atuaram em plataformas digitais e possuíam entre 24 e 34 anos quando do estabelecimento do contato.

\section{Resultados}

\section{Indícios da precarização das condições de trabalho}

Nesta seção, valemo-nos de indicadores apontados por Mick e Lima (2013) como indícios da crescente precarização nas condições de trabalho dos jornalistas brasileiros: as baixas remunerações, o acúmulo de empregos para complementação de renda e as jornadas de trabalho que ultrapassam o previsto em lei.

Entre os 238 colaboradores do questionário "Perfil dos jornalistas profissionais do Estado de São Paulo", 39\% relataram receber uma remuneração inferior ao menor piso salarial para a categoria no ano de referência (atinente a cinco horas de trabalho por dia), com uma faixa de $19 \%$ (quase um quinto dos respondentes) obtendo rendimentos entre um e dois salários mínimos. Outros 37\% se enquadraram nos pisos vigentes para cinco e sete horas de trabalho por dia, e somente $24 \%$ possuíam uma renda mensal superior a sete salários mínimos (desse total, 16\% com remuneração entre sete e dez salários, $5 \%$ entre 10 e 15 e 3\% no topo da lista, com receita média superior a 15 salários) $)^{15}$ (Gráfico 2$)$.

12. Essa diretriz nos alinha à sugestão de Duarte (2004) de utilizar "mediadores" como fontes privilegiadas para entrada em uma esfera especializada do mundo vivido, bem como à técnica do snowball, delineada por Bernard (2006) como tática apropriada para inserção em um campo social no qual a população a ser estudada encontra-se espalhada por uma área geograficamente ampla (nesse caso, a extensão do Estado de São Paulo).

13. Somente um pequeno fragmento desses depoimentos é apresentado neste trabalho.

14. A identidade dos entrevistados foi preservada garantindo o sigilo das fontes.

15. Algumas informações são fundamentais para esclarecer os resultados obtidos. No período de realização das duas enquetes que compuseram uma parcela do corpus de análise desta pesquisa, o salário mínimo brasileiro era de R \$ 880,00, segundo Decreto n. 8.616 de 29 de dezembro de 2015. Conforme dados do Sindicato dos Jornalistas do Estado de São Paulo (sJsp), o piso salarial dos jornalistas que atuam 
GRÁFICO 2

Rendimento médio

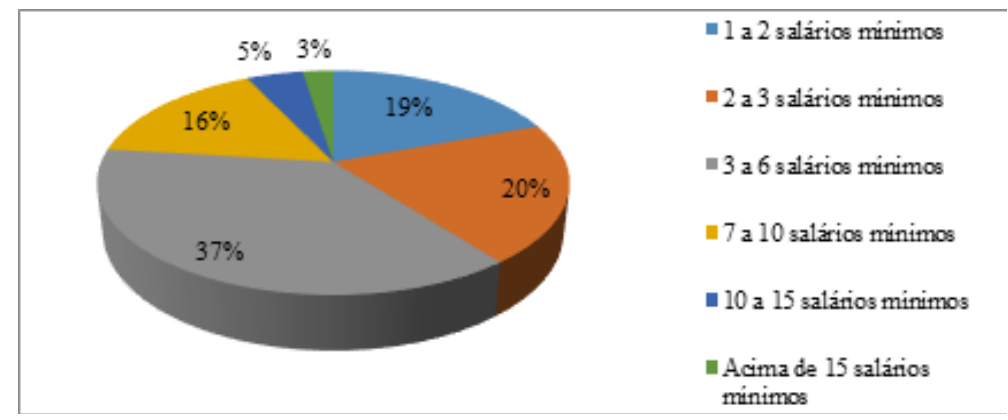

Fonte: Autor. Dados da pesquisa "Perfil dos jornalistas profissionais do Estado de São Paulo".

Já no tocante às jornadas diárias de trabalho, os dados gerais confirmam a tendência de desobediência das empresas às normas previstas em lei pela CLT: mais de um terço do total dos participantes (35\%) afirmou trabalhar em regime superior a 10 horas diárias, $46 \%$ indicaram atuar em jornadas de até 8 horas por dia e somente 19\% se enquadraram completamente na legislação vigente (Gráfico 3).

\section{GRÁFICO 3}

Horas trabalhadas por dia (média)

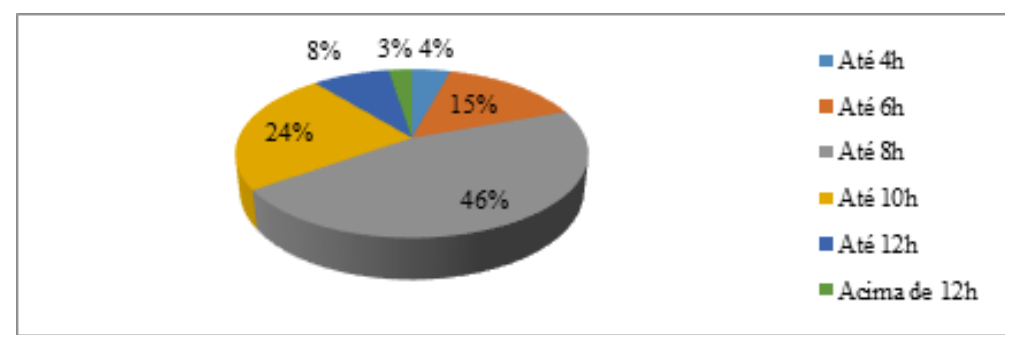

Fonte: Autor. Dados da pesquisa “Perfil dos jornalistas profissionais do Estado de São Paulo”.

Por fim, no que concerne à prestação de atividades extras para complementação da renda familiar, $41 \%$ dos 238 colaboradores da enquete "Perfil dos jornalistas profissionais do Estado de São Paulo" declararam acumular funções para compor suas remunerações mensais (Gráfico 4). Entre as atividades listadas na caixa de comentários do questionário, sobressaem: freelancers para publicações da área, produções audiovisuais ou assessoria de imprensa, revisão de materiais escritos (livros,

na capital no período de 01 de junho de 2016 a 31 de maio de 2017 para uma jornada de cinco horas corresponde a $\mathrm{R} \$ 2.986,00$ (pouco mais de três salários mínimos), enquanto em jornadas de sete horas o valor é elevado para $\mathrm{R} \$ 4.777,21$ (aproximadamente cinco e meio salários mínimos). Em empresas do interior e do litoral do Estado, o piso para cinco horas é de $\mathrm{R} \$ 2.420,00$ e para sete horas, $\mathrm{R} \$ 3.872,00$. 
teses, artigos), docência em Ensino Superior (predominantemente em cursos de Comunicação) e negócios dissociados do campo jornalístico, como consultoria, aluguel de imóveis e até mesmo artesanato.

GRÁFICO 4

Prestação de serviços para complementação de renda familiar

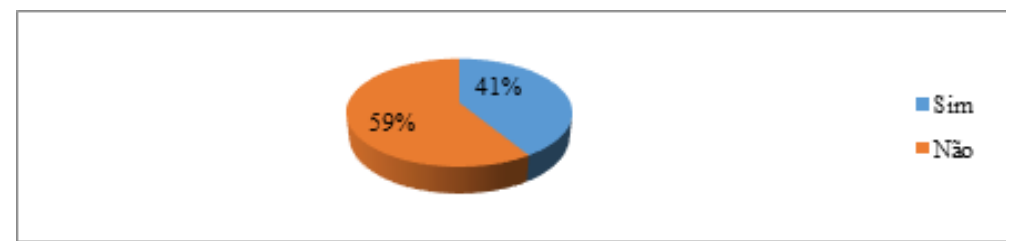

Fonte: Autor. Dados da pesquisa “Perfil dos jornalistas profissionais do Estado de São Paulo”.

Em síntese: em sinergia às investigações empreendidas em âmbito nacional, é possível assinalar que as empresas de comunicação do Estado de São Paulo apresentam propensão ao descumprimento de pagamento do piso salarial e de desobediência à jornada de trabalho diária estabelecida para a categoria. A baixa remuneração leva os jornalistas a buscarem fontes complementares de renda, o que, a seu turno, gera uma sobrecarga de tarefas que tornam os tempos de trabalho ainda mais extensos.

Mas os indícios de precarização do campo jornalístico em São Paulo não se restringem ao espectro da remuneração, das jornadas e do acúmulo de atividades. Os dados coletados pelo questionário "Perfil dos jornalistas profissionais do Estado de São Paulo" também sustentam outra via de deterioração das condições de trabalho dos comunicadores: dos 238 respondentes, mais da metade (55\%) indicou estar em uma empresa de comunicação por um período de um a três anos, seguidos de $27 \%$ atuando para o mesmo empregador entre três e seis anos, e somente $18 \%$ vinculados por mais de seis anos a uma mesma organização (Gráfico 5).

GRÁFICO 5

Tempo de trabalho na empresa atual

\begin{tabular}{|l|l|} 
& $=1 \mathrm{a} 3 \mathrm{anos}$ \\
& $=3 \mathrm{a} 6 \mathrm{annos}$ \\
& $=6 \mathrm{a} 10 \mathrm{annos}$ \\
& $=10 \mathrm{a} 15$ anos \\
& $=15 \mathrm{a} 20$ anos \\
& $=$ Acima de 20 anos
\end{tabular}

Fonte: Autor. Dados da pesquisa "Perfil dos jornalistas profissionais do Estado de São Paulo”.

Já os resultados do questionário "Condições de trabalho dos jornalistas profissionais do Estado de São Paulo", aplicado a 318 participantes, apontam também 
para um predomínio por formas precárias de contratação: somente 33\% dos respondentes alegaram atuar sob o regime da CLT e $8 \%$ como servidores públicos, enquanto $18 \%$ se declaravam freelancers, outros $18 \%$ se identificavam como PJs e $9 \%$ exerciam suas atividades em contratos de prestação de serviços. Ou seja, a metade dos participantes desta enquete (50\%) alegou trabalhar em um regime flexível de contratação (Gráfico 6).

GRÁFICO 6

Formas de contratação
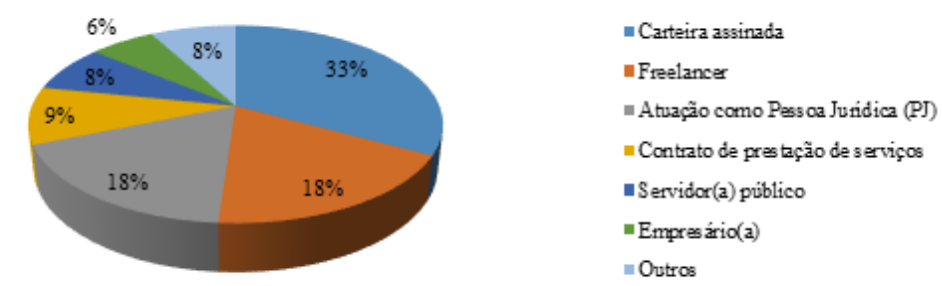

Fonte: Autor. Dados da pesquisa "Condições de trabalho dos jornalistas profissionais do Estado de São Paulo".

\section{Os efeitos da precarização segmentados por faixas etárias}

Uma parcela substancial dos percentuais gerais apresentados torna-se mais preocupante quando estes são discriminados por faixas etárias, pois sinalizam para a acentuação da deterioração das condições de trabalho dos jornalistas com maior experiência no setor: no questionário aplicado a 238 profissionais da área, na faixa de 31 a 70 anos, os gráficos de tempo de permanência em uma mesma empresa mantêm uma inclinação para vínculos de até três anos: entre 31 e 40 anos os números atingem 45\%; entre 41 e 50 anos 33\%; e entre 51 e 70 anos, 36\% (Gráfico 7).

GRÁFICO 7

Tempo de trabalho na empresa atual

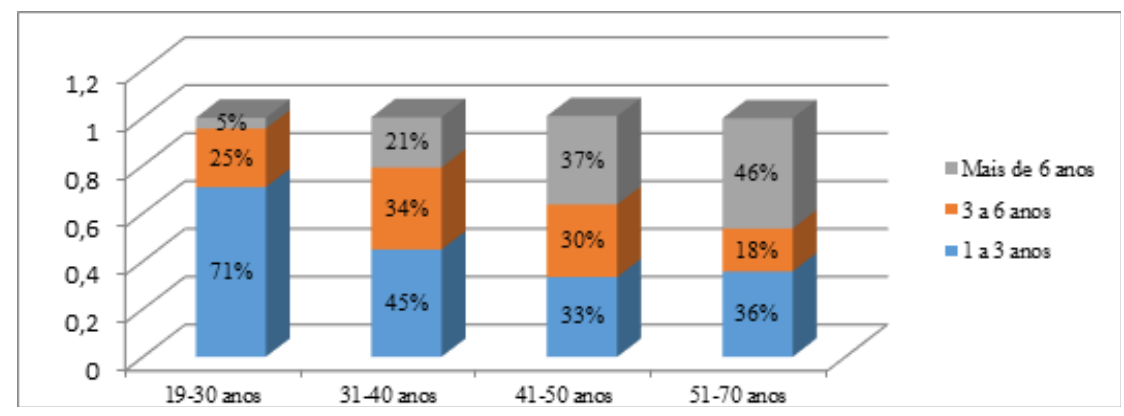

Fonte: Autor. Dados da pesquisa "Perfil dos jornalistas profissionais do Estado de São Paulo". 
No tocante às formas de contratação, os resultados do questionário "Condições de trabalho dos jornalistas profissionais do Estado de São Paulo" corroboram tal indício de precarização da atividade dos jornalistas de idade mais avançada - tradicionalmente responsáveis por contribuírem na constituição de uma "identidade ocupacional" entre os novatos. Se entre os comunicadores de 19 a 30 anos o índice de registrados sob o regime de CLT atinge os $56 \%$ (seguido por freelancers, $17 \% \mathrm{e}$ pJs, 11\%), na faixa entre 31 e 40 anos essa taxa recua para 36\% (com 20\% de freelancers e 17\% de PJs); entre 41 e 50 anos novo declínio de profissionais com CLT (somente 22\%, seguidos de 26\% de pJs e 13\% de freelancers); entre 51 e 60 anos o índice atinge $20 \%$ (com 22\% de freelancers e $18 \%$ de PJs); e por fim, na última faixa etária, entre 61 e 70 anos, o número de comunicadores com CLT atinge seu valor mais baixo, de 19\% (comprimidos entre a taxa de 22\% de PJs, 19\% de contratos de prestação de serviços e $13 \%$ de freelancers) (Gráfico 8).

\section{GRÁFICO 8}

Formas de contratação

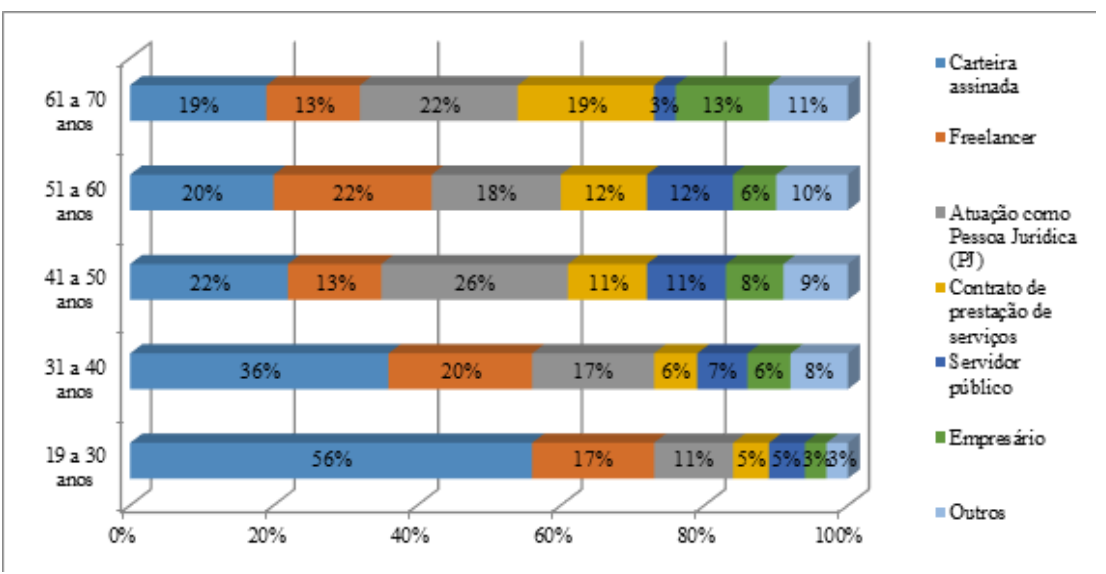

Fonte: Autor. Dados da pesquisa "Condições de trabalho dos jornalistas profissionais do Estado de São Paulo".

A fragilização de postos de trabalho mais estáveis para jornalistas de maior experiência na área implica que uma parcela não desprezável desses profissionais se vê compelida a complementar sua renda mensal com prestação de serviços extras. Se na faixa de 19 a 30 anos pouco mais de um terço dos respondentes (ou 38\% da amostra) afirmam acumular funções com vistas a uma maior remuneração, entre os jornalistas de 31 a 40 anos esses índices se elevam para $42 \%$ - até atingirem seu ápice no bloco de 41 a 50 anos, com 52\% dos trabalhadores (ou mais da metade do total) exercendo atividades extras. Os percentuais decrescem suavemente no último estrato, de 51 a 70 anos, em que $46 \%$ dos colaboradores relataram prestar serviços para complementar a renda (Gráfico 9). 
GRÁFICO 9

Prestação de serviços para complementação de renda familiar

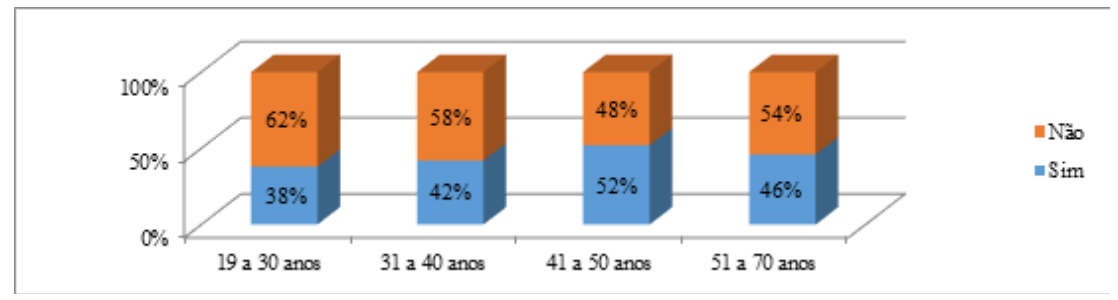

Fonte: Autor. Dados da pesquisa "Perfil dos jornalistas profissionais do Estado de São Paulo".

Desestruturações dessa natureza no mundo do trabalho dos jornalistas foram recentemente sinalizadas por Adghirni (2012), mormente devido às sucessivas ondas de demissões de profissionais com salários mais altos (substituídos por recém-formados de baixa remuneração e maior adaptabilidade às normas político-editoriais das organizações) e pelo enxugamento dos postos de trabalho que muitos deles ocupavam.

O diagnóstico inverte dinâmicas já exaustivamente analisadas que ressaltavam a instabilidade profissional exclusiva a jornalistas jovens, ainda em inserção no mercado. A título de ilustração, no contexto francês, Ruellan (2001) destacara a expansão do serviço de freelancers entre novatos na profissão, que "antes de poderem ascender a postos de trabalho estáveis, devem passar por uma fase de empregos descontínuos e precários, constituindo uma direção de ajuste que permite aos empregadores julgar sua capacidade (de trabalhar e se adequar à empresa) por um período relativamente longo (muitas vezes vários anos)” (p. 142). No Brasil, Heloani (2005) e Fígaro (2013) também haviam frisado esta inclinação do mundo do trabalho dos comunicadores em oferecer postos precários a principiantes na carreira que, enquanto buscavam melhores oportunidades, submetiam-se a jornadas extenuantes (entre oito a dez horas por dia) com contratos flexíveis. Considerava-se, inclusive, que esse período de instabilidade era naturalizado pelo ingressante na carreira, possibilitando a "aceitação e participação em rituais de socialização profissional que admitem os tempos, a paciência, a maleabilidade, e mesmo a submissão, como experiências necessárias para obter o direito a um trabalho" (Ruellan, 2001, p. 147).

Os deslocamentos nos modos de inserção no mercado também repercutem, por sua vez, em teses caras às sociologias das redações, que descreveram, em outros contextos, um aprendizado tácito da "cultura profissional" nas rotinas diárias por intermédio do contato com repórteres e editores mais versados no ofício. Os dados levantados por esta investigação revelam uma desarticulação na lógica de integração à “comunidade jornalística", tal como propuseram os estudos seminais de Bourdieu (1996), Ruellan (2004) e Traquina (2005). 
Para Ruellan, a história do jornalismo "é a ilustração perfeita do benefício (socialização, proteção, identidade) que os trabalhadores podem retirar de um processo corporativo que consistiu em fechar o território profissional, em reservá-lo a uma categoria especial de membros em detrimento de outros que se viram, assim, excluídos" (2004, p. 18). Na esteira, a transmissão dos valores do ofício, partilhados coletivamente, transcorre no interior de uma comunidade dos jornalistas, tendo em vista que "as notícias são produzidas por profissionais que partilham uma 'forma de ver' comum, isto é, uma cultura noticiosa comum" (Traquina, 2005, p. 28). Bourdieu (1996) e Traquina (2005) chegaram inclusive a nomear os grupos profissionais organizados nas redações como tribos/comunidades interpretativas, que possuiriam cada qual um conjunto de "saberes" legitimados, bem como seus indivíduos socialmente estimados, detentores de autoridade para repassar conhecimentos adquiridos no decorrer da trajetória. Destarte, na interação com jornalistas mais velhos os novatos se envolveriam em um processo de acumulação de saberes acerca da profissão e de maturação do news judgement adequado ao veículo. Na medida em que se aprende o 'jornalês' e seus valores, os iniciantes são moldados conforme a lógica da redação e são valorizados segundo essa competência linguística dominante, que é o principal capital nesse mercado particular, "capaz de impor a lei de formação de preços mais favorável aos seus produtos e de propiciar o lucro simbólico correspondente" (Bourdieu, 1996, p. 57).

Bourdieu (1996) constata que a natureza simbólica da institucionalização das práticas jornalísticas é o que possibilita a um jovem repórter poder transitar da condição de foca à de experiente, apreendendo gradativamente as particularidades da redação, os saberes partilhados pelo grupo e o vocabulário legitimado no campo. Enfim, por essa leitura clássica do processo de inserção nessa zona do mundo do trabalho as competências técnicas do jornalista decorrem do reconhecimento de sua legitimidade pelo grupo, e os profissionais mais versados na cultura do ofício assumem um papel fundamental na transmissão dos valores comuns partilhados na redação.

Em estudo recente de Pereira (2013), advoga-se em favor da permanência dessa forma de socialização e aquisição de saberes legitimados no mundo do trabalho dos jornalistas também em redações digitais. Por meio de entrevistas com profissionais que atuam em empresas do ramo, o autor defende que o aprendizado no ambiente de trabalho e na interlocução com os pares ainda é determinante se comparado aos eventuais cursos de treinamento oferecidos pelos veículos aos seus contratados. Conforme Pereira, as especificidades da organização de mídia para a qual o profissional atua e sua trajetória e aspirações na área delineiam "as condições em que os jornalistas negociam aquilo que precisa ser aprendido, como certo tipo de conhecimento pode ser adquirido, e o grau de autonomia que ele ou ela irão ter para propor alteraçóes e experimentações" (p. 139). 
Nas entrevistas semiestruturadas conduzidas no decurso da presente investigação a persistência dessa forma típica de aprendizado no mundo do trabalho dos jornalistas também foi perceptível. Quando indagados sobre suas relações com colegas e superiores nas redações em que atuaram, muitos dos entrevistados sustentaram a tradicional segmentação entre teoria e prática para argumentarem em favor do aprendizado tácito da cultura jornalística a partir de sua efetiva inserção no mercado, sobretudo no que diz respeito ao domínio dos softwares utilizados para formatação e publicação dos materiais que produziam para os veículos (softwares estes muitas vezes desenvolvidos pelos departamentos de tecnologia da informação das próprias empresas).

Mas também não é possível desconsiderar depoimentos que atestam, nas redações digitais, uma desqualificação dos saberes adquiridos ao longo de uma trajetória e transmitidos para os jovens ingressantes no jornalismo, em patente contraste à tese de Pereira (2013). A título de exemplo, segue o discurso de uma profissional de 27 anos com passagem em diversas agências de conteúdo:

Não dá pra acomodar. Antigamente as pessoas faziam curso de datilografia, um curso de, sei lá, edição de imagens né, revelação fotográfica, e elas trabalhavam com aquilo durante 30, 40 anos, e viravam quase uma peça de museu dentro das redações, porque ninguém ia demiti-las por conta da experiência, do conhecimento, da bagagem, mas sabiam que os processos já tinham sido otimizados, automatizados. E hoje em dia não há espaço para peças de museu não. Museu, tem museu virtual, assim, ninguém vai ficar mantendo um funcionário, por mais experiente que ele seja, se ele não buscar se atualizar, entender que em cinco anos o jornalismo já vai ter mudado de novo (Depoimento extraído de entrevista concedida ao pesquisador em 25 de agosto de 2016).

Esse diagnóstico é partilhado por uma repórter de 34 anos (a idade mais avançada dentre o conjunto dos entrevistados) que percebeu um impacto negativo nas oportunidades de emprego oferecidas a ela após o início das ondas de demissão ocorridas em diferentes veículos de imprensa:

\footnotetext{
Porque eles colocam o salário muito baixo, e hoje não interessa mais a sua experiência, sua bagagem, sua vivência na profissão, entendeu? Se você tiver um recém-formado que faça o mesmo que você, eles não querem saber, eles vão pagar menos. Então é por isso que a gente vê muito jornalista bom, excelentes profissionais, que estão migrando pra outras áreas, pra negócios próprios, pra outras profissões. Porque ninguém quer mais segurar aquele profissional lá, com aquele salário, entendeu? (Depoimento extraído de entrevista concedida ao pesquisador em 24 de agosto de 2016).
} 
Outra entrevistada, também acima dos 30 anos (mais especificamente com 33 na ocasião da realização desta etapa da pesquisa) e experiência de mais de sete anos como editora assistente de uma agência focada em produção noticiosa para o mercado financeiro, lamentou as mudanças empreendidas na organização em que atuava quando, após diversas reestruturações internas (que se iniciaram em 2011), uma nova mentalidade gerencial foi introduzida no ambiente de trabalho. Se até então a empresa era reconhecida por agregar profissionais experientes de competência inquestionável, dali em diante muitos deles foram exonerados e os remanescentes tolhidos de ascender a postos mais altos na redação (além de desprestigiados a despeito de sua excelência na área). A organização passou a se enfocar em cursos de treinamento nos quais se contratava em escala considerável jovens jornalistas para ocuparem as vagas deixadas pelos demitidos. Para a entrevistada, nesses cursos os recém-formados eram literalmente adestrados pela empresa "para fazerem aquilo que se precisa pagando-se uma mão de obra mais barata" (Depoimento extraído de entrevista concedida ao pesquisador em 19 de abril de 2016).

Um quarto interlocutor, de 28 anos e exercendo atualmente a função de editor e redator da homepage de um portal de notícias de relevância nacional, após relatar que na redação da empresa em que atua havia uma predominância por pessoas de até 35 anos, solteiras (ou casadas com outros jornalistas), sem dependentes, e que estão sobrevivendo aos “passaralhos”, chega à mesma constatação da entrevistada anterior:

\footnotetext{
É difícil ver agora pessoas que tem 30 anos de casa. Porque o que aconteceu muito esse ano, que foram três demissões em massa, foi um ano bem atípico, é que eles acabaram demitindo pessoas que são muito antigas, com, por exemplo, 30 anos de casa, porque, acredito eu, vale mais a pena (pro empresário né) você demitir alguém que tem 30 anos de casa e vai custar uma fortuna, vale mais a pena demitir ele agora do que ano que vem que vai ser 31 anos de casa. Então eles estão demitindo pessoas antigas e mantendo pessoas novas, com salários mais baixos em relação aos mais antigos, e são pessoas que são solteiras, que não têm problema em ficar muito tempo no trabalho (Depoimento extraído de entrevista concedida ao pesquisador em 24 de agosto de 2016).
}

$\mathrm{Na}$ visão de um quinto entrevistado (também com 28 anos e experiência predominante em agências de notícia com enfoque no mercado financeiro), há que se destacar a existência inclusive de uma política de cortes direcionada especificamente àqueles profissionais que vão adquirindo mais tempo de casa. Em suas palavras: "É uma lógica no mínimo assustadora pra um profissional que se forma e se dedica àquilo, saber que ele vai ficar na empresa ganhando pouco por muito tempo até que aquele pouco, pela correção, por alguma coisa, seja muito suficiente pra ele ser 
demitido" (Depoimento extraído de entrevista concedida ao pesquisador em 24 de junho de 2016).

Com base nesses cinco depoimentos supracitados, revela-se notório o fato de que, além da visível precarização das condições de trabalho de jornalistas com maior vivência nas redações, caminha em paralelo um processo crescente de desconstrução das formas tradicionais de inserção e de aprendizado da "cultura jornalística" nessa esfera do mundo do trabalho. Ademais, produz-se paulatinamente um volume de profissionais experientes (dispensados pelas empresas jornalísticas) disputando novos cargos com recém-egressos de faculdades de comunicação, em organizações com alta rotatividade de postos de trabalho e submetendo-se às remunerações inferiores, jornadas extenuantes e formas de contratação flexíveis para poderem garantir a renda familiar - o que degrada ainda mais as condições de trabalho no setor, como conclui uma das interlocutoras da pesquisa: "Hoje, o cenário propicia muito melhores condições pros empregadores do que pros empregados, porque eles têm a possibilidade de contratar pessoas altamente capacitadas por um salário bem baixo, ou pessoas realmente parrudas por um salário mediano, que seria o piso normal, segundo o Sindicato" (Depoimento extraído de entrevista concedida ao pesquisador em 25 de agosto de 2016).

\section{Conclusões}

O presente trabalho possibilitou apreender, no contexto do Estado de São Paulo, os efeitos das mutações no mundo do trabalho dos jornalistas no que diz respeito à deterioração das condições laborais. Os elevados índices de demissão nos veículos de imprensa somados à alta taxa de profissionais sem ocupação fixa propiciam o surgimento de um "exército de reserva" - uma mão de obra qualificada disposta a assumir postos flexíveis sem garantia de estabilidade ocupacional o que, por consequência, agrava também a situação daqueles que se encontram em empregos formais, gerando um ciclo vicioso de precarização. Essa conjuntura explica as altas taxas de mobilidade detectadas, os percentuais substanciais de comunicadores que atuam em descumprimento às normas vigentes para a categoria do ponto de vista da jornada e das remunerações, e o significativo volume de profissionais que necessitam aglutinar funções para complementar o rendimento familiar.

Mas os efeitos das reestruturações no campo jornalístico tornam-se ainda mais alarmantes em face dos resultados que apontam para uma degradação acentuada das condições de trabalho dos veteranos no Estado de São Paulo. Não obstante ser um indicativo de rompimento nas expectativas de progressão na carreira (uma vez que a instabilidade contratual, os deslocamentos de postos e a necessidade de 
complementação na renda não retrocedem com o passar dos anos), ainda sinaliza para uma preocupante corrosão das práticas de socialização dos novos repórteres, que outrora sedimentavam uma "comunidade interpretativa" (Traquina, 2005) nas redações, pautada por laços ocupacionais partilhados. A consequência mais nociva dessa tendência é a aceleração da dissolução dos elos que produziam um mundo comum de jornalistas-trabalhadores, agora dispersos em redações fragmentadas ou pior, em home offices nos quais a identificação com a profissão pode se restringir à conclusão da tarefa em curso.

\section{Referências Bibliográficas}

Adghirni, Zélia. (2001), “Jornalismo online e identidade profissional do jornalista”. Comunicação e Espaço Público, 1 (1): 49-67.

Adghirni, Zélia. (2012), "Mudanças estruturais no jornalismo: travessia de uma zona de turbulência”. In: Pereira, Fábio; Moura, Dione \& Adghirni, Zélia (orgs.). Jornalismo e sociedade: teorias e metodologias. Florianópolis, Insular, pp. 61-79.

BERNARD, H. Russel. (2006), Research methods in anthropology: qualitative and quantitative approaches. Oxford, Altamira Press.

Bourdieu, Pierre (1996), Sobre a televisão. Rio de Janeiro, Jorge Zahar.

Duarte, Rosália. (2004), “Entrevistas em pesquisas qualitativas”. Educar, 24: 213-225.

Fígaro, Roseli. (2013) “Atividade de comunicação e trabalho dos jornalistas”. E-Compós, 16 (1): $1-20$.

Gans, Hans (1979), Deciding What's News: a study of CBS Evening News, NBC Nightly News, Newsweek, and Time. Evanston, Northwestern University Press.

HeloAni, José. (2005), Mudanças no mundo do trabalho e impactos na qualidade de vida do jornalista. São Paulo, FGV.

Huws, Ursula (2014), Labor in the digital economy. Nova York, Monthly Review Press.

Mick, Jaques \& Lima, Samuel. (2013), Perfil do jornalista brasileiro: características demográficas, politicas e do trabalho jornalistico em 2012. Florianópolis, Insular.

Minayo, Maria \& SAnches, Odécio. (1993), "Quantitativo-qualitativo: oposição ou complementaridade?”. Cadernos de Saúde Pública, 9 (3): 239-262.

Moretzsohn, Sylvia. (2002), Jornalismo em tempo real: o fetiche da velocidade. Rio de Janeiro, Revan.

Neveu, Erik. (2000), "Le genre du journalisme : des ambivalences de la féminisation d'une profession”. Politix, 13 (51): 179-212.

Pereira, Fábio. (2013), “A study on Brazilian web journalists' professional careers”. Communication \& Society, 26 (4): 127-151. 
Ruellan, Denis. (2001), “Socialisation des journalistes entrant dans la profession”. Quaderni, 45: 137-152.

Ruellan, Denis. (2004), “Grupo profissional e mercado de trabalho do jornalismo”. Comunicação e Sociedade, 5: 9-24.

Traquina, Nelson. (2005), Teorias do Jornalismo. Florianópolis, Insular, vol. 2.

Tuchman, Gaye. (1973), “Making news by doing work: routinizing the unexpected”. American Journal of Sociology, 79 (1): 110-131.

\section{Resumo}

A precarização das condições de trabalho dos jornalistas de São Paulo segmentada por faixas etárias: uma identidade profissional em risco?

Este artigo parte do contexto de reestruturações produtivas no mundo do trabalho dos jornalistas, caracterizado por sistemáticas demissões e alta rotatividade de profissionais nas redações. Por meio da aplicação de dois questionários e 15 entrevistas semiestruturadas com comunicadores que atuavam no Estado de São Paulo entre dezembro de 2015 e janeiro de 2017, busca-se inicialmente avaliar os impactos dessas reestruturações nas condições de trabalho dos jornalistas. Em seguida, os dados são segmentados por faixas etárias, revelando uma precarização ascendente dos mais experientes no setor. Argumenta-se que essa tendência pode estar debilitando a construção de uma identidade profissional entre as novas gerações de repórteres.

Palavras-chave: Jornalismo; Precarização; Condições de trabalho; Identidade profissional. 


\section{Abstract}

The precarization of work conditions of journalists in São Paulo segmented by age groups: a professional identity at risk?

This article starts with the context of productive restructurings in the world of work of journalists, characterized by systematic layoffs and high turnover of professionals in newsrooms. Through the application of two surveys and 15 semi-structured interviews with communicators who were working in the State of São Paulo between December 2015 and January 2017, initially it seeks to assess the impacts of these restructurings on the work conditions of journalists. Next, the data are segmented by age groups, revealing an upward precarization of the most experienced in the sector. It is argued that this trend may be undermining the construction of a professional identity among new generations of reporters.

Keywords: Journalism; Precarization; Work conditions; Professional identity.

Texto recebido em 30/5/2018 e aprovado em 8/11/2018.

DOI: $10.11606 / 0103-2070 . t s .2019 .146626$

Thales Vilela Lelo é doutor em ciências sociais pela Universidade Estadual de Campinas e professor da Universidade do Estado de Minas Gerais. E-mail: thales.lelo@gmail.com. 